ISSN : 2746-7155 (Online), ISSN : 1978-4996 (Print)

MAKILA:Jurnal Penelitian Kehutanan Volume 14, Nomor 1 (57-72)

DOI : http://doi.org/10.30598/makila.v14i1.2508

®2020 Jurusan Kehutanan UNPATTI

\title{
Pemetaan Daerah Rawan Erosi Di DAS Wae Batu Merah Kota Ambon
}

\author{
(Mapping of Erosion-prone Areas in the Wae Batu Merah Watershed in Ambon City)
}

Lidia V. Intopiana ${ }^{1}$, Jusmy D. Putuhena ${ }^{2}$, Aryanto Boreel ${ }^{3}$

\author{
1) Mahasiswa Jurusan Kehutanan Fakultas Pertanian Universitas Pattimura \\ 2),3) Pengajar Jurusan Kehutanan Fakultas Pertanian Universitas Pattimura, Jln. Ir. M. Putuhena, Kampus Poka \\ Ambon 97233 \\ Email: Lidiaforester@gmail.com
}

\begin{abstract}
ABSTRAK
This study aimed to identify the factors that cause erosion, map erosion-prone areas, and determine conservation directions that can be carried out on regions indicated by erosion in the Wae Batu Merah watershed. In this study, erosion forming parameters will be overlapped. The USLE (Universal Soil Loss Equation) method was used as a parameter to create erosion. The results showed that erosion factors that greatly affected the erosion incidence in the Wae Batu Merah watershed, namely, slope factors and crop management factors and conservation measures, and as much as erosion were dominated by very large classes with an area of 558.21 ha or $52.67 \%$ alone. The smallest is the medium class, with an area of 54.57 ha or $5.15 \%$. Conservation directives carried out on regions indicated by erosion in the Wae Batu Merah watershed were the direction of the vegetative method, which is reforestation, planting trees in the form of durian trees, and GMO sengon trees, making parks in residential areas, and building mechanical terraces.
\end{abstract}

KEYWORDS: Watershed, Erosion, Rainfall, Soil, Slope, Land Cover

\section{INTISARI}

Penelitian ini bertujuan untuk mengidentifikasi faktor - faktor penyebab erosi, memetakan daerah rawan erosi, dan menentukan arahan konservasi yang dapat dilakukan terhadap daerah yang terindikasi erosi di DAS Wae Batu Merah. Dalam penelitian ini parameter - parameter pembentuk erosi akan ditumpang susun. Metode USLE (Universal Soil Loss Equation) dipakai sebagai parameter pembentuk erosi. Hasil penelitian menunjukan bahwa faktor erosi yang sangat mempengaruhi kejadian erosi di DAS Wae Batu Merah yaitu, faktor kemiringan lereng dan faktor pengelolaan tanaman dan tindakan konservasi, dan seberan erosi didominasi oleh kelas sangat berat dengan luas 558,21 ha atau sebesar 52,67 \% sedangkan yang paling kecil adalah kelas sedang dengan luas 54,57 ha atau sebesar 5,15 \%. Arahan konservasi yang dilakukan terhadap daerah yang terindikasi erosi di DAS Wae Batu Merah adalah arahan metode vegetatif yaitu tindakan reboisasi, penanaman pohon berupa pohon durian dan pohon sengon transgenik, pembuatan taman pada areal permukiman, sendangkan metoe mekanik yaitu pembuatan terasering.

KATA KUNCI : DAS, Erosi, Curah Hujan, Tanah, Kelerengan, Penutupan Lahan. 


\section{PENDAHULUAN}

Daerah Aliran Sungai (DAS) adalah suatu wilayah daratan yang secara topografi dibatasi oleh punggung gunung yang dapat menampung dan menyimpan air hujan yang kemudian disalurkkan ke laut melalui sungai utama. (Asdak, 2014)

Dalam Peraturan Menteri Kehutanan Republik Indonesia, No. P. 61/Menhut-II/2014, Tentang Monitoring Dan Evaluasi Pengelolaan Daerah Aliran Sungai menguraikan bahwa Daerah Aliran Sungai (DAS) dapat dipandang sebagai sistem alami yang menjadi tempat berlangsungnya proses biofisik hidrologis maupun kegiatan sosial, ekonomi masyarakat yang kompleks.

Kelestarian DAS dan ekosistem di dalamnya mempunyai peranan yang sangat penting untuk menjaga keseimbangan alam, artinya semua komponen yang membentuk suatu ekosistem DAS saling berinteraksi atau memiliki hubungan timbal balik yang baik dan optimal.

Hal ini juga dijelaskam dalam Peraturan Menteri Kehutanan Republik Indonesia, tentang monitoring dan evaluasi pengelolaan Daerah Aliran Sungai bahwa di dalam DAS kualitas ekosistem dilihat dari produktivitas lahan, aliran permukaan, fluktasi debit, erosi dan sedimentasi.

Menurut Arsyad, 2010 dalam Dewi et al. (2012) menyebutkan bahwa erosi adalah hilangnya atau terkikisnya suatu tanah atau bagian tanah dari suatu tempat yang diangkut oleh air atau angin ke tempat lain. Erosi di DAS umumnya terjadi karena adanya pemanfaatan lahan yang tidak mengindahkan kaidah konservasi tanah dan air.

Kerusakan ekosistem DAS di wilayah kota Ambon sangat rentan karena : Daerah aliran sungai (DAS) yang berada di Pulau Ambon mempunyai ukuran yang sangat sempit ( $<1500 \mathrm{Ha}$ ). Topografi dominan berbukit hingga bergunung (73\%), wilayah kota Ambon memiliki kelerengan (> $30 \%$ ). Akibatnya Wilayah Kota Ambon mempunyai ketersediaan lahan yang layak untuk mendukung aktifitas pembangunan sangatlah terbatas, dan sangat rawan terhadap kerusakan lingkungan (Nuhung, 2012)

Daerah Aliran Sungai Batu Merah sebagai pengatur siklus hidrolgi menentukan baik buruknya konservasi tanah da air, dan juga nilai jasa lingkungan (Putuhena 2013; Putuhena 2014: Latuihamallo dan Putuhena 2016; Oszaer dan Putuhena 2017). Konservasi tanah dan air yang baik akan menetukan besar kecilnya terjadinya kejadian kekritisan suatu DAS termasuk bencana erosi maupun longksor. Hal ini tentunya terjadi pada DAS di Kota Ambon termasuk DAS Batu Merah.

Menurut Putuhena (2013) DAS Wae Batu merah termasuk dalam DAS kritis di Indonesia, dijelaskan juga bahwa kondisi kritis ini disebabkan karena perubahan penutupan lahan di kota Ambon yang lebih banyak didominisasi oleh pemukiman penduduk dan infrastruktur pendukung lainnya.

DAS Wae Batu Merah telah mengalami penurunan fungsi menjadi Area Penggunaan Lain (APL) untuk pemukiman, jalan, atau kebun campur. Luas APL pada wilayah DAS Wae Batu Merah mencapai 4.021,20 Ha atau 50,64 \% (Rencana Kerja Pembangunan Daerah Kota Ambon 2016). Hal ini, 
mendorong terjadinya ketidakseimbangan ekosistem DAS yang salah satunya mengakibatkan terjadinya erosi.

Untuk mempertahankan kondisi kelestarian DAS akibat dari kejadian erosi tanah yang telah menghilangkan unsur tanah yang subur, diperlukan tindakan pencegahan agar erosi yang terjadi tidak melebihi batas erosi yang dapat diperbolehkan. Jika erosi telah terjadi maka diperlukan suatu tindakan pencegahan dengan cara rehabilitasi dan konservasi lahan agar erosi yang terjadi tidak melebihi batas erosi yang diperbolehkan. Untuk itu, sebelum dilakukan tindakan rehabilitasi dan konservasi lahan perlu diketahui titik atau daerah yang terindikasi terjadinya erosi. Melalui analisis geospasial spasial dapat diprediksi daerah atau wilayah yang terindikasi erosi. Dengan menggunakan metode USLE (Universal Soil Loss Equation) yang umum digunakan untuk memperediksi laju erosi, akan mempermudah peneliti untuk memproses dan menghasilkan peta daerah rawan erosi. Oleh karena itu penelitian ini bertujuan untuk mengindentifikasi faktor - faktor penyebab erosi, memetakan daerah rawan erosi, dan menentukan arahan konservasi terhadap daerah yang terindikasi erosi di DAS Wae Batu Merah.

\section{METODE PENELITIAN}

\section{Lokasi dan Waktu Penelitian}

Penelitian ini dilaksanakan di Daerah Aliran Sungai (DAS) Wae Batu Merah Kecamatan Sirimau Kota Ambon. Kegiatan penelitian ini dilakukan pada Bulan September sampai Oktober 2018.

\section{Alat dan Bahan}

Alat dan bahan yang digunakan dalam penelitian ini berupa : Data DEM 2015, Peta tanah DAS Wae Batu Merah, ArcGis 10.1, Microsoft Exel 2010, Laptop, GPS, Kamera Handphone, Alat tulis menulis.

\section{Teknik Pengumpulan Data}

Adapun pengumpulan data yang dilakukan dalam peneltian ini menggunakan data sekunder berupa Data curah hujan dari Badan Meteorologi Klimatologi dan Geofisika (BMKG) Kota Ambon, data jenis tanah dari studi pustaka, dan data pengelolaan tanaman dan tindakan konservasi tanah yang diperoleh dari studi pustaka. Data yang dikumpulkan secara primer adalah data kemiringan lereng dari penggunaan data DEM dan pengecekan data pengelolaan tanaman dilapangan.

\section{Variabel Penelitian}

Variabel dalam penelitian ini adalah data curah hujan Pulau Ambon selama 10 tahun terakhir yang diolah menggunakan rumus Lenvain, 1989 untuk mendapatkan nilai Erosivitas Hujan (R), jenis tanah digunakan data sekunder dari penelitian Putuhena (2013) di DAS Wae Batu Merah dan nilai 
Erodibilitas (K) menggunakan nilai K dari Supriadi (2017), panjang dan kemiringan lereng (LS) diolah dari data DEM, pengunaan lahan dalam penelitian ini meliputi faktor pengelolaan tanaman dan tindakan konservasi tanah (CP). Interpretasi citra Landsat 8 tahun 2017 digunakan untuk pembuatan peta faktor CP. Untuk menentukan nilai CP digunakan perkiraan nilai faktor CP berbagai jenis penggunaan lahan di Jawa (Abdurachman dkk.,1984; Ambar dan Syafrudin, 1979 dalam Asdak, 2014).

\section{Analisis Data}

Proses ini menggunakan pendekatan Sistem Informasi Geografis (SIG) dengan perangkat lunak ArcGis 10.1. Proses pengolahan data dilakukan untuk memperoleh nilai faktor dari masing masing parameter erosi yang diperlukan untuk tahap klasifikasi bahaya erosi.

- Klasifikasi Curah Hujan

Tabel 1. Klasifikasi Curah Hujan

\begin{tabular}{|c|c|c|}
\hline Kelas & $\begin{array}{c}\text { Curah Hujan } \\
\mathrm{mm} / \text { tahun }\end{array}$ & Klasifikasi \\
\hline 1 & $<1500$ & Sangat Rendah \\
\hline 2 & $1500-<2000$ & Rendah \\
\hline 3 & $2000-<2500$ & Sedang \\
\hline 4 & $2500-<3000$ & Tinggi \\
\hline 5 & $>3000$ & Sangat Tinggi \\
\hline
\end{tabular}

Sumber : Kementerian Kehutanan (2013)

- Klasifikasi Jenis Tanah

Tabel 2. Klasifikasi Jenis Tanah

\begin{tabular}{|c|c|c|}
\hline Kelas & Jenis Tanah & Klasifikasi \\
\hline 1 & $\begin{array}{c}\text { Aluvial, Glei, Planosol, } \\
\text { Hidromerf, Laterik air } \\
\text { tanah }\end{array}$ & $\begin{array}{c}\text { Tidak } \\
\text { Peka }\end{array}$ \\
\hline 2 & Latosol & $\begin{array}{c}\text { Kurang } \\
\text { Peka }\end{array}$ \\
\hline 3 & $\begin{array}{c}\text { Brown forest soil, non } \\
\text { calcic brown, mediteran }\end{array}$ & Agak Peka \\
\hline 4 & $\begin{array}{c}\text { Andosol, Laterit, } \\
\text { Grumusol, Podsol, } \\
\text { Podsolic }\end{array}$ & Peka \\
\hline 5 & $\begin{array}{c}\text { Regosol, Litosol, } \\
\text { Organosol, Renzina }\end{array}$ & $\begin{array}{c}\text { Sangat } \\
\text { Peka }\end{array}$ \\
\hline
\end{tabular}

Sumber : SK. Menteri Pertanian (1980) No. 837/Kpts/Um/11/1980 
- Klasifikasi Jenis Tanah

Tabel 3. Klasifikasi Jenis Tanah

\begin{tabular}{|c|c|c|}
\hline Kelas & Jenis Tanah & Klasifikasi \\
\hline 1 & $\begin{array}{c}\text { Aluvial, Glei, Planosol, } \\
\text { Hidromerf, Laterik air } \\
\text { tanah }\end{array}$ & $\begin{array}{c}\text { Tidak } \\
\text { Peka }\end{array}$ \\
\hline 2 & Latosol & $\begin{array}{c}\text { Kurang } \\
\text { Peka }\end{array}$ \\
\hline 3 & $\begin{array}{c}\text { Brown forest soil, non } \\
\text { calcic brown, mediteran }\end{array}$ & Agak Peka \\
\hline 4 & $\begin{array}{c}\text { Andosol, Laterit, } \\
\text { Grumusol, Podsol, } \\
\text { Podsolic }\end{array}$ & Peka \\
\hline 5 & $\begin{array}{c}\text { Regosol, Litosol, } \\
\text { Organosol, Renzina }\end{array}$ & $\begin{array}{c}\text { Sangat } \\
\text { Peka }\end{array}$ \\
\hline
\end{tabular}

Sumber: SK. Menteri Pertanian (1980) No. 837/Kpts/Um/11/1980

- Klasifikasi Kemiringan Lereng

Tabel 4. Klasifikasi Kemiringan Lereng

\begin{tabular}{|c|c|c|}
\hline Kelas & Kelerengan & Klasifikasi \\
\hline 1 & $0-8$ & Datar \\
\hline 2 & $8-15$ & Landai \\
\hline 3 & $15-25$ & Agak Curam \\
\hline 4 & $25-45$ & Curam \\
\hline 5 & $>45$ & Sangat Curam \\
\hline
\end{tabular}

Sumber : Kementerian Kehutanan (2013)

- Klasifikasi Penutupan Lahan

Tabel 5. Klasifikasi Penutupan Lahan

\begin{tabular}{|c|c|c|}
\hline $\begin{array}{c}\text { Kela } \\
\mathrm{s}\end{array}$ & Kategori & Klasifikasi \\
\hline 1 & Sangat Baik & $\begin{array}{c}\text { Hutan Lahan Kering } \\
\text { Primer }\end{array}$ \\
\hline 2 & Baik & $\begin{array}{c}\text { Hutan Lahan Kering } \\
\text { Sekunder }\end{array}$ \\
\hline 3 & Sedang & Semak Belukar \\
\hline 4 & Buruk & Permukiman \\
\hline
\end{tabular}

Sumber : Ditjen Planologi Kehutanan (2009)

Dalam penelitian ini parameter - parameter pembentuk erosi akan ditumpang susun atau disebut sebagai proses overlay. Proses overlay dilakukan dengan cara input keempat peta tematik yaitu peta curah hujan, peta tanah, peta kelerengan dan peta penutupan lahan. Peta - peta tersebut 
sebelum di overlay telah mengalami proses pengeditan data atribut. Metode USLE (Universal Soil Loss Equation) dipakai sebagai parameter pembentuk erosi.

$$
\mathrm{A}=\text { R.K.LS.CP }
$$

Dimana :

A = Banyaknya tanah yang hilang per tahun

$\mathrm{R} \quad=$ Faktor Erosivitas Hujan

$\mathrm{K}=$ Faktor Erodibilitas Tanah

LS = Faktor Kemiringan Lereng

$\mathrm{CP}=$ Faktor Penutupan dan Penggunaan Lahan

Kemudian untuk klasifikasi tingkat Erosi memakai Peraturan Kementerian Kehutanan No

P.4/V-SET/2013 Tentang Petunjuk Teknis Penyusunan Data Spasial Lahan Kritis.

Tabel 6. Klasifikasi Bahaya Erosi

\begin{tabular}{|c|c|c|}
\hline $\begin{array}{c}\text { Kelas } \\
\text { Bahaya } \\
\text { Erosi }\end{array}$ & $\begin{array}{c}\text { Laju Erosi } \\
\text { (ton/ha/tahun) }\end{array}$ & Keterangan \\
\hline I & $<15$ & $\begin{array}{c}\text { Sangat } \\
\text { Ringan }\end{array}$ \\
\hline II & $15-60$ & Ringan \\
\hline III & $60-180$ & Sedang \\
\hline IV & $180-480$ & Berat \\
\hline V & $>480$ & Sangat Berat \\
\hline
\end{tabular}

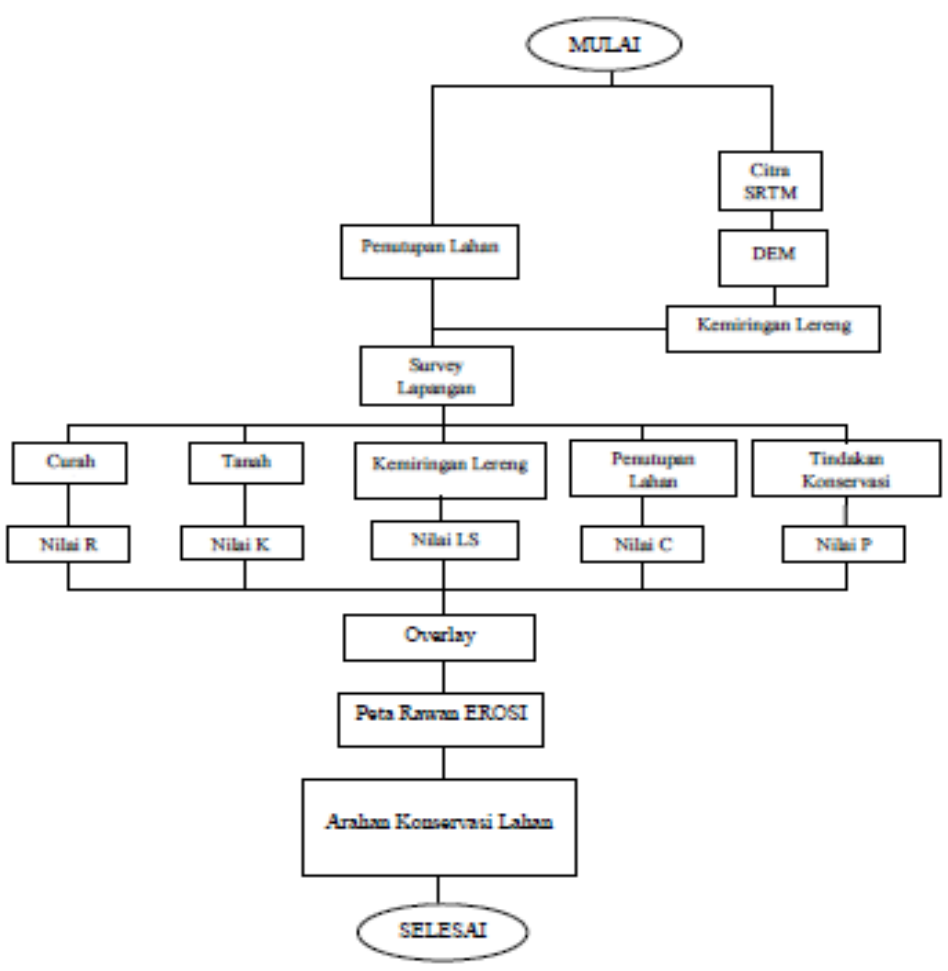

Gambar 1. Diagram Alir Penelitin 


\section{ASIL DAN PEMBAHASAN}

\section{Analisis faktor - faktor penyebab Erosi}

\section{Faktor Erosivitas Hujan (R)}

Tabel. 7. Nilai Erosivitas hujan di DAS Wae Batu Merah

\begin{tabular}{clcc}
\hline No & Bulan & $\begin{array}{c}\text { CH Bulanan } \\
(\mathbf{c m})\end{array}$ & $\begin{array}{c}\mathbf{R}=\mathbf{2 , 2 1} \mathbf{X ~ C H} \\
\mathbf{1 . 3 6}\end{array}$ \\
\hline 1 & Januari & 200,8 & $1.351,93$ \\
\hline 2 & Febuari & 140,5 & 849,73 \\
\hline 3 & Maret & 130,6 & 770,06 \\
\hline 4 & April & 192,2 & $1.292,83$ \\
\hline 5 & Mei & 571,4 & $5.923,82$ \\
\hline 6 & Juni & 683,2 & $7.460,64$ \\
\hline 7 & Juli & 808,7 & $9.474,55$ \\
\hline 8 & Agustus & 517,9 & $5.259,67$ \\
\hline 9 & September & 299,8 & $2.513,49$ \\
\hline 10 & Oktober & 148,1 & 881,5 \\
\hline 11 & November & 77,8 & 403,39 \\
\hline 12 & Desember & 160,9 & 998,34 \\
\hline \multicolumn{3}{c}{ TOTAL } \\
\hline
\end{tabular}

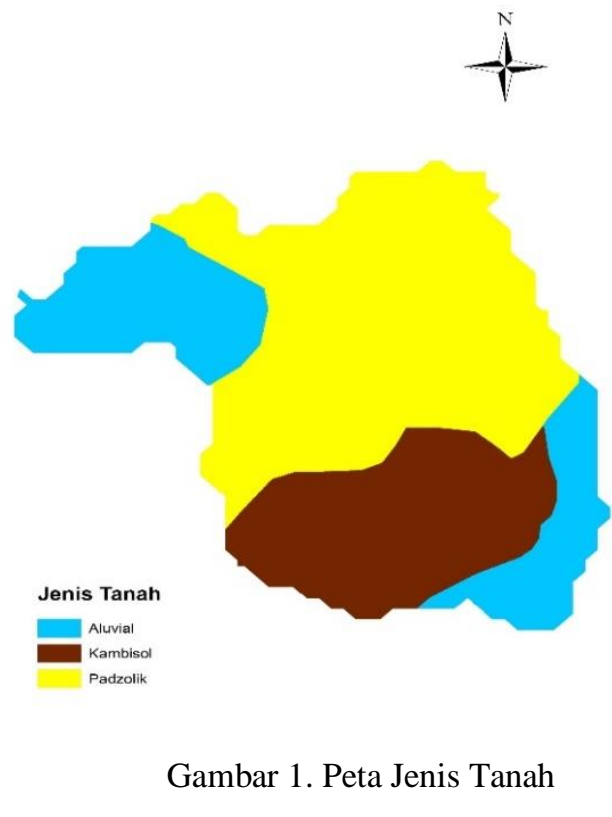

Hasil analisis menunjukan curah hujan terendah terjadi pada bulan November sebesar 778 $\mathrm{mm}$ dan curah hujan tertinggi terjadi pada bulan Juli sebesar $8.087 \mathrm{~mm}$. Besarnya erosivitas hujan tahunan yang terjadi di DAS Wae Batu Merah adalah 3.717,99.

\section{Faktor Erodibilitas Tanah (K)}

Tabel 8. Jenis Tanah di Das Wae Batu Merah.

\begin{tabular}{cccc}
\hline \multirow{2}{*}{ No } & \multirow{2}{*}{ Jenis Tanah } & \multicolumn{2}{c}{ Luas } \\
\cline { 3 - 4 } & & Ha & $\mathbf{0}$ \\
\hline 1 & Alluvial & 253,1 & 23,88 \\
\hline 2 & Kambisol & 265,45 & 25,04 \\
\hline 3 & Padsolik & 541,37 & 51,08 \\
\hline & Total & $\mathbf{1 . 0 5 9 , 9 1}$ & $\mathbf{1 0 0}$ \\
\hline
\end{tabular}

Data analisis menunjukan presentasi jenis tanah padsolik memiliki luasan yang paling besar dengan luasan 541,37 ha atau 51,08\%, diikuti oleh jenis tanah Kambisol seluas 265,45 ha atau 25,04\% dan Alluvial seluas 253,10 ha atau 23,88\%. Berikut tabel nilai Erodibilitas (K) pada setiap jenis tanah. 
Tabel 9. Tabel Nilai Erodibilitas (K) pada Berbagai Jenis Tanah di Lokasi Penelitian

\begin{tabular}{ccc}
\hline No & Jenis Tanah & Nilai $\mathbf{K}$ \\
\hline 1 & Alluvial & 0,178 \\
\hline 2 & Kambisol & 0,22 \\
\hline 3 & Padsolik & 0,225 \\
\hline & Sumber: Supriadi, 2017
\end{tabular}

Semakin besar nilai koefisien, maka tanah akan semakin peka terhadap erosi dan sebaliknya. Jika nilai koefisien kecil maka kepekaan tanah terhadap erosi semakin rendah. Pernyataan ini juga sesuai dengan pernyataan Supriadi, 2017 yang menyatakan bahwa nilai erodibilitas yang tinggi akan mudah tererosi dibandingkan dengan nilai erodibilitas yang rendah.

\section{Panjang dan Kemiringan Lereng}

Tabel 10. Kelas Kelerengan di Das Wae Batu Merah

\begin{tabular}{ccccc}
\hline \multirow{2}{*}{ No } & \multirow{2}{*}{ Kelerengan } & \multirow{2}{*}{ Kategori } & \multicolumn{2}{c}{ Luas } \\
\cline { 3 - 5 } & & Ha & $\%$ \\
\hline 1 & $0-8 \%$ & Datar & 74,91 & 7,06 \\
\hline 2 & $8-15 \%$ & Landai & 183,14 & 17,28 \\
\hline 3 & $15-25 \%$ & $\begin{array}{c}\text { Agak } \\
\text { Curam }\end{array}$ & 427,25 & 40,31 \\
\hline 4 & $25-45 \%$ & Curam & 227,63 & 21,48 \\
\hline 5 & $>45 \%$ & $\begin{array}{c}\text { Sangat } \\
\text { Curam }\end{array}$ & 146,97 & 13,87 \\
\hline & TOTAL & & $\mathbf{1 0 5 9 , 9 1}$ & $\mathbf{1 0 0}$ \\
\hline
\end{tabular}

Berdasarkan presentasi luas kelas lereng dengan kategori agak curam memiliki luas yang mendominasi area penelitian seluas 427,25 ha atau sekitar 40,31\% dari total DAS Wae Batu Merah. Besarnya nilai LS ditentukan berdasarkan kemiringan lereng sebagaimana disajikan dalam Tabel 11.

Tabel 11. Nilai Panjang dan Kelerengan (LS) di Lokasi Penelitian

\begin{tabular}{ccc}
\hline No & $\begin{array}{c}\text { Kemiringan } \\
\text { Lereng (\%) }\end{array}$ & Nilai LS \\
\hline 1 & $0-8$ & 0,25 \\
\hline 2 & $8-15$ & 1,2 \\
\hline 3 & $15-25$ & 4,25 \\
\hline 4 & $25-45$ & 9,5 \\
\hline 5 & $>45$ & 12 \\
\hline
\end{tabular}

Sumber: Widiatmaka, 2007 dalam Putuhena 2013 


\section{Faktor Pengelolaan Tanaman (C) dan Tindakan Konservasi (P)}

Ada empat 4 (empat) tipe penggunaan lahan di lokasi penelitian berdasarkan hasil interpretasi citra landsat 8, empat (4) tipe tersebut adalah hutan lahan kering primer, hutan lahan kering sekunder, semak belukar, dan permukiman

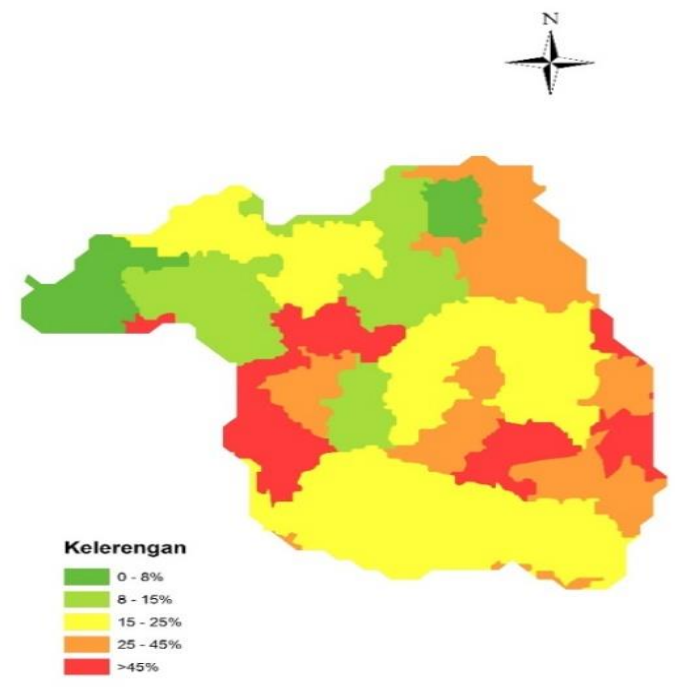

Gambar 3. Peta Kemiringan Lereng

Tabel 12. Klasifikasi penggunaan lahan dan nilai faktor CP

\begin{tabular}{cccc}
\hline No & Klasifikasi & Kode & $\begin{array}{c}\text { Nilai } \\
\text { CP }\end{array}$ \\
\hline 1 & $\begin{array}{c}\text { Hutan Lahan Kering } \\
\text { Primer }\end{array}$ & HLKP & 0,001 \\
\hline 2 & $\begin{array}{c}\text { Hutan Lahan Kering } \\
\text { Sekunder }\end{array}$ & HLKS & 0,005 \\
\hline 3 & Semak Belukar & SB & 0,3 \\
\hline 4 & Permukiman & PM & 1 \\
\hline Sumber : Widiatmaka, 2007 dalam Putuhena 2013
\end{tabular}

Dari Tabel 12, menunjukan bahwa semakin besar nilai koefisien artinya pengaruh penggunaan lahan tersebut semakin buruk. 


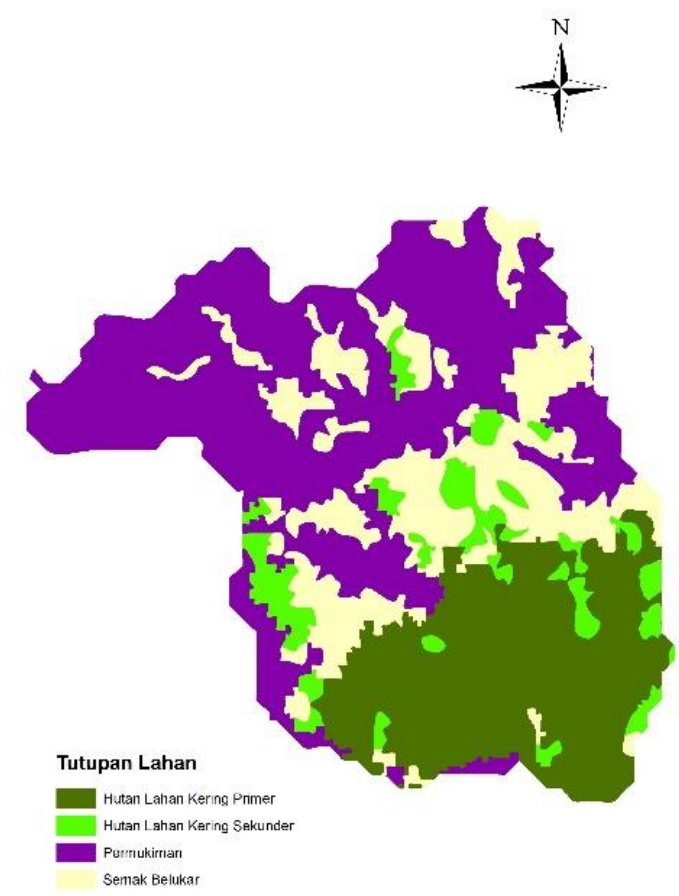

Gambar 3. Peta Penutupan Lahan

\section{Pendugaan Wilayah Rawan Erosi di DAS Wae Batu Merah}

Tingkat kerawanan erosi di DAS Wae Batu Merah dilakukan dengan pendekatan geospasial dengan melakukan proses overlay terhadap parameter input yang telah dijelaskan pada bagian sebelumnya dengan menggunakan formula pendugaan erosi USLE. Berikut tabel perhitungan nilai erosi dan luas sebaran erosi yang terjadi di DAS Wae Batu Merah Kota Ambon.

Tabel. 13. Nilai erosi dan luas sebaran erosi DAS Wae Batu Merah

\begin{tabular}{ccccc}
\hline \multirow{2}{*}{ No } & \multirow{2}{*}{ Kategori } & $\begin{array}{c}\text { Erossi } \\
\text { (ton/ha/thn }\end{array}$ & \multicolumn{2}{c}{ Jumlah } \\
\cline { 4 - 5 } 1 & & Ha & \% \\
\hline 2 & Rangat & $<15$ & 289,5 & 27,31 \\
\hline 3 & Ringan & $15-60$ & 69,85 & 6,59 \\
\hline 4 & Sedang & $60-180$ & 54,57 & 5,15 \\
\hline 5 & Berat & $180-480$ & 87,75 & 8,28 \\
\hline \multirow{3}{*}{$\begin{array}{c}\text { Sangat } \\
\text { Berat }\end{array}$} & $>480$ & 558,21 & 52,67 \\
\hline \multicolumn{3}{c}{ TOTAL } & Sumber : Hasil analisis data, 2019 & $\mathbf{1 0 0}$ \\
\hline
\end{tabular}

Hasil analisis menunjukan bahwa nilai erosi yang terjadi adalah sebesar 189.595,83 ton/ha/thn. 


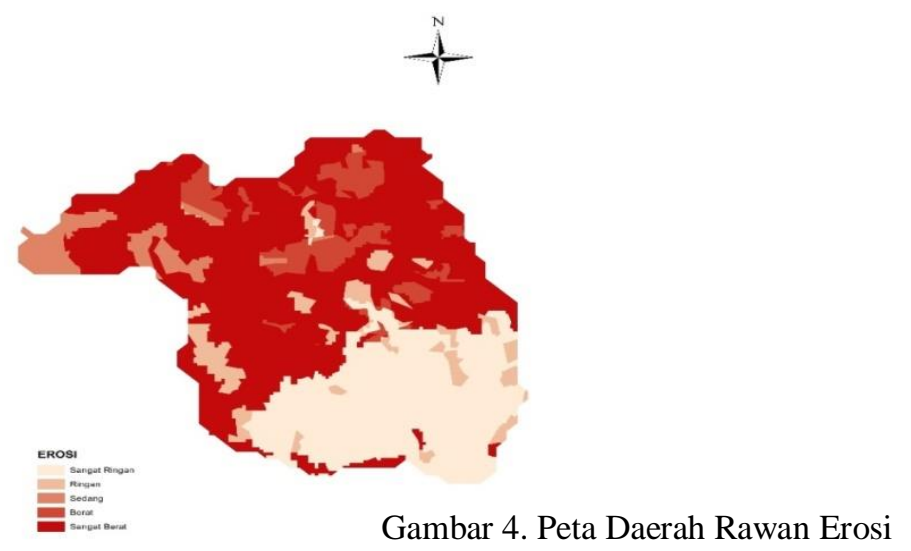

Dalam usaha untuk mencegah kejadian erosi, kita dapat memperhatikan faktor-faktor yang mempengaruhi terjadinya erosi. Dalam penelitian ini ada beberapa faktor yang dapat dikendalikan atau dirakayasa sehingga dapat memperkecil besarnya nilai erosi yang terjadi seperti misalnya faktor kemiringan lereng dan faktor pengelolaan dan tindakan konservasi tanah.

Tabel 14. Erosi ditinjau dari nilai $\mathrm{K}$, LS dan CP

\begin{tabular}{|c|c|c|c|c|c|}
\hline$\overline{\mathrm{LS}}$ & $\overline{\mathrm{K}}$ & "HLKP & "HLKS & $\overline{\mathrm{SB}}$ & PRMK \\
\hline \multirow{3}{*}{$\begin{array}{c}0-8 \\
\%\end{array}$} & $\mathrm{AL}$ & 0,17 & 0,83 & 49,64 & 165,45 \\
\hline & KAM & 0,20 & 1,02 & 61,35 & 204,49 \\
\hline & PAD & 0,21 & 1,05 & 62,74 & 209,14 \\
\hline \multirow{3}{*}{$\begin{array}{c}8-15 \\
\%\end{array}$} & $\mathrm{AL}$ & 0,79 & 3,97 & 238,25 & 794,16 \\
\hline & KAM & 0,98 & 4,91 & 294,47 & 981,55 \\
\hline & PAD & 1,00 & 5,02 & 301,16 & 1003,86 \\
\hline \multirow{3}{*}{$\begin{array}{c}15- \\
25 \%\end{array}$} & AL & 2,81 & 14,06 & 843,80 & 2812,66 \\
\hline & KAM & 3,48 & 17,38 & 1042,90 & 3476,32 \\
\hline & PAD & 3,56 & 17,78 & 1066,60 & 3555,33 \\
\hline \multirow{3}{*}{$\begin{array}{c}25- \\
45 \%\end{array}$} & $\mathrm{AL}$ & 6,29 & 31,44 & 1886,14 & 6287,13 \\
\hline & KAM & 7,77 & 38,85 & 2331,18 & 7770,61 \\
\hline & PAD & 7,95 & 39,74 & 2384,16 & 7947,21 \\
\hline \multirow{3}{*}{$>45 \%$} & $\mathrm{AL}$ & 7,94 & 39,71 & 2382,49 & 7941,64 \\
\hline & KAM & 9,82 & 49,08 & 2944,65 & 9815,50 \\
\hline & PAD & 10,04 & 50,19 & 3011,58 & 10038,58 \\
\hline
\end{tabular}

Sumber : Hasil analisis, 2019 
Dari Tabel 14, yang menampilkan nilai erosi ditinjau dari ketiga faktor pembentuk erosi yaitu, faktor erodibilitas (K), faktor kemiringan lereng (LS), faktor pengelolaan dan tindakan konservasi tanah (CP) menunjukan bahwa nilai terendah erosi terjadi dengan karakteristik lahan berupa hutan lahan kering primer, memiliki jenis tanah alluvium dan berada pada tingkat kelerengan $0-8 \%$ dengan total nilai erosi 0,17 ton. Nilai tertinggi erosi sebesar 10038,58 ton terjadi pada karakteristik lahan berupa permukiman, memiliki jenis tanah padsolik, dan berada pada tingkat kelerengan $>45 \%$. Nilai erosi terendah berada pada hutan lahan kering primer dengan jenis tanah alluvium dan berada pada tingkat kelerengan 15 - $25 \%$ dengan nilai erosi sebesar 2,81 ton. Selanjutnya karakteristik hutan lahan kering sekunder yang memiliki jenis tanah padsolik dengan tingkat kelerengan $>45 \%$ dipakai sebagai nilai tengah dalam perhitungan nilai erosi aktual di DAS Wae Batu Merah. Namun, jika nilai K dipandang sama dan dicari nilai rataannya, maka hasil kedua faktor LS dan CP disajikan pada tabel 14.

Dari tabel 14 ini dapat ditentukan daerah dengan ketentuan karakteristik mana saja yang diarahkan untuk tindakan pencegahan erosi. Dari tabel 15. dapat dilihat bahwa daerah dengan tingkat kemiringan lereng 0 - 8\% sampai 15 - 25\% dengan penutupan lahan berupa hutan lahan kering primer dan hutan lahan kering sekunder memiliki nilai erosi yang tidak melebihi nilai erosi yang ditoleransi. Artinya, pada daerah ini tdak perlu dilakukan tindakan konservasi. Daerah daerah yang perlu dilakukan tindakan konservasi adalah daerah dengan tingkat kemiringan lereng 0 - 8\% dan 8 - 15\% dengan penutupan dan penggunaan lahan berupa semak belukar dan permukiman. Kemudian, daerah dengan tingkat kemiringan lereng 15 - $25 \%$ dengan penutupan lahan berupa hutan lahan kering sekunder, semak belukar, dan permukiman. Untuk daerah dengan kemiringan lereng $25-45 \%$ dan $>45 \%$ pada setiap penutupan dan penggunaan lahan perlu dilakukan tindakan konservasi. 
Tabel 15. Erosi ditinjau dari LS VS CP dan Arahan Konservasi

\begin{tabular}{|c|c|c|c|c|}
\hline LS & $\mathrm{CP}$ & Erosi Aktual & $\mathbf{T}$ & Arahan \\
\hline \multirow{4}{*}{$0-8 \%$} & Hutan Lahan Kering Primer & 0,44 & 17,15 & Dipertahankan \\
\hline & Hutan Lahan Kering Sekunder & 2,2 & 17,15 & Dipertahankan \\
\hline & Semak Belukar & 131,9 & 17,15 & Va \\
\hline & Permukiman & 439,65 & 17,15 & $\mathrm{Vc}$ \\
\hline \multirow{4}{*}{$8-15 \%$} & Hutan Lahan Kering Primer & 2,11 & 17,15 & Dipertahankan \\
\hline & Hutan Lahan Kering Sekunder & 10,55 & 17,15 & Dipertahankan \\
\hline & Semak Belukar & 633,1 & 17,15 & $\mathrm{Vb} 1$ \\
\hline & Permukiman & 2110,33 & 17,15 & Vc \\
\hline \multirow{4}{*}{$15-25 \%$} & Hutan Lahan Kering Primer & 9,84 & 17,15 & Dipertahankan \\
\hline & Hutan Lahan Kering Sekunder & 41,92 & 17,15 & Reboisasi \\
\hline & Semak Belukar & 2242,23 & 17,15 & $\mathrm{Vb} 1$ \\
\hline & Permukiman & 7474,1 & 17,15 & Vc \\
\hline \multirow{4}{*}{$25-45 \%$} & Hutan Lahan Kering Primer & 22 & 17,15 & $\mathrm{Va}$ \\
\hline & Hutan Lahan Kering Sekunder & 83,53 & 17,15 & Va \\
\hline & Semak Belukar & 5012,04 & 17,15 & Vb1b2Ma \\
\hline & Permukiman & 16706,81 & 17,15 & $\mathrm{VcMa}$ \\
\hline \multirow{4}{*}{$>45 \%$} & Hutan Lahan Kering Primer & 21,1 & 17,15 & $\mathrm{Va}$ \\
\hline & Hutan Lahan Kering Sekunder & 105,52 & 17,15 & $\mathrm{Va}$ \\
\hline & Semak Belukar & 6331 & 17,15 & Vb1b2Ma \\
\hline & Permukiman & 21103,33 & 17,15 & VcMa \\
\hline
\end{tabular}

\section{Keterangan :}

LS : Kemiringan Lereng

$\mathrm{CP}$ : Penutupan/Penggunaan Lahan

Nilai T : Nilai erosi yang diperbolehkan. Nilai ini bersumber dari data penelitian Supriadi (2017)

Cara Vegetatif (V) :
a. Reboisasi
b. Penanaman Pohon :
1. Pohon Durian
2. Sengon Transgenik
c. Pembuatan Taman

Cara Mekanik (M) :

a. Terasering Arahan Pencegahan Erosi Arahan tindakan konservasi yang disarankan dalam penelitian ini berupa arahan dengan metode vegetatif dan mekanik. Berikut penjelasan dari masing - masing arahan yang disarankan. 
a. Reboisasi. Kegiatan ini dimaksudkan untuk mengembalikan fungsi hutan pada suatu kawasan yang dulunya merupakan kawasan hutan lindung. Kegiatan ini, difokuskan pada daerah dengan kelerengan 0 - 8 \% dengan penutupan lahan berupa semak belukar, kemudian kelerengan 25 - 45 \% dan kelerengan > $45 \%$ dengan penutupan lahan berupa hutan lahan kering primer dan hutan lahan kering sekunder.

b. Pemilihan Jenis Pohon. Jenis pohon yang disarankan untuk ditanam pada kawasan rawan erosi adalah jenis durian montong dan jenis sengon transgenik. Diharapkan bahwa kedua jenis tanaman ini selain berfungsi untuk mencegah erosi, diharapkan juga dapat membantu perekonomian masyarakat setempat. Kegiatan ini difokuskan pada daerah dengan kelerengan 8 - $15 \%$, kelerengan 15 - $25 \%$, kelerengan 25 - $45 \%$ dan > $45 \%$ dengan penutupan lahan berupa semak belukar.

c. Pembuatan Taman. Pembuatan Taman bertujuan untuk menghindari terjadinya kejadian erosi pada kawasan permukiman. Arahan konservasi pembuatan taman difokuskan pada areal permukiman pada setiap kelas kelerengan mulai dari 0 - $8 \%$ sampai kelerengan $>45 \%$ yang memiliki lahan yang kosong tanpa vegetasi ataupun minim vegetasi. Masyarakat dapat menanam beberapa pohon, bunga-bunga dan yang terpenting adalah menanam rumput. Rumput yang disarankan adalah rumput gajah mini karena rumput ini cukup murah, tidak memerlukan banyak perawatan dan tahan cuaca.

- $\quad$ Metode Mekanik

Tujuan dari metode mekanik adalah untuk merekayasa panjang lereng agar dapat memperkecil laju aliran permukaan dan memperbesar peresapan air. Usaha konservasi ini dilakukan pada daerah dengan kelerengan 25 - $45 \%$ dan $>45 \%$ dengan penggunanaan lahan berupa daerah permukiman. Dari metode mekanik ini, ada beberapa usaha yang dapat dilakukan untuk mengurangai nilai erosi aktual pada suatu daerah, misalanya pembuatuan teras bangku, teras individu, teras kebun, teras guludan dan sengkedan.

\section{KESIMPULAN}

\section{Kesimpulan}

1. Hasil penelitian menunjukan bahwa semua faktor mempengaruhi kejadian erosi di DAS Wae Batu Merah antara lain, erosivitas hujan, erodibilitas tanah, kemiringan lereng, penutupan dan tindakan konservasi. Dimana faktor yang sangat berpengaruh adalah faktor kemiringan lereng dan faktor pengelolaan tanaman dan tindakan konservasi.

2. Seberan erosi didominasi oleh kelas sangat berat dengan luas 558,21 ha atau sebesar 52,67 \%, sedangkan yang paling kecil adalah kelas sedang dengan luas 54,57 ha atau sebesar 5,15\%.

3. Arahan konservasi yang dilakukan terhadap daerah yang terindikasi erosi di DAS Wae Batu Merah adalah arahan metode vegetatif yaitu tindakan reboisasi, penanaman pohon berupa pohon 
4. durian dan pohon sengon transgenik, pembuatan taman pada areal permukiman, sedangkan metode mekanik yaitu pembuatan terasering.

\section{Saran}

1. Berdasarkan hasil penelitian, diketahui bahwa tingkat kerawanan erosi berat dan sangat berat mayoritas terjadi pada kawasan pemukiman dan semak belukar. Untuk itu penulis menyarankan agar pihak terkait lebih memperhatikan wilayah tersebut sebagai wilayah prioritas penanggulangan erosi.

2. Mayoritas wilayah tidak melakukan tindakan konservasi tanah dan air apapun sehingga memperbesar terjadinya erosi. Pemanfaatan tanah hendaknya dengan memperhatikan konservasi tanah dan air sehingga mengurangi terjadinya erosi pada tanah.

3. Perlu dilakukan penelitian lebih lanjut mengenai kondisi lapangan agar informasi yang dihasilkan lebih rinci atau detail.

\section{DAFTAR PUSTAKA}

Asdak, C. 2014. Hidrologi dan Pengelolaan Daerah Aliran Sungai. Edisi Keenam, Gadjah Mada University Press. Yogyakarta. 647 hal.

Dewi. I.G.A.S.U, Trigunasih. N.M, Kusmawati, T. 2012. Prediksi Erosi dan Perencanaan Konservasi Tanah dan Air pada DAS Saba. E-Journal Agroekoteknologi Tropika. Vol 1.

Nuhung, B. 2012. Pemetaan Tingkat Bahaya Erosi Menggunakan Sistem Informasi Geografi Pada DAS Wae Ruhu (DAS Prioritas I) Di Kota Ambon. Skripsi.Universitas Pattimura. Ambon.

Latuihamalo J., Jusmy D. Putuhena. 2016. Analisis Nilai Guna Hutan Sebagai Penyedia Air Bersih dan Implementasi PES (Payment for Ecosystem Sevices) bagi Pemilik Dusun di Hutan Lindung Sirimau Kota Ambon. Jurnal Hutan Pulau Pulau Kecil. Vol 1 Nomor 1, Halaman 44-52.

Oszaer R., J. D. Putuhena. 2017. Analysis of Sustainability Management of River Flow of Wae Batu Gajah City Ambon. International Journal of Science and Research (IJSR). Vol 6. Issu 10. www.ijsr.net.

Peraturan Direktur Jendral Bina Pengelolaan Daerah Aliran Sungai Dan Perhutanan Sosial No. P. 3/V-SET/2013 Tentang Pedoman Identifikasi Karakteristik Daerah Aliran Sungai.

Peraturan Kementerian Kehutanan No P.4/V-SET/2013 Tentang Petunjuk Teknis Penyusunan Data Spasial Lahan Kritis.

Peraturan Menteri Kehutanan Republik Indonesia, No. P. 61/Menhut-II/2014, Tentang Monitoring Dan Evaluasi Pengelolaan Daerah Aliran Sungai.

Peraturan Walikota Ambon No. 19 Tahun 2015 Tentang Rencana Kerja Pembangunan Daerah (RKPD) Kota Ambon Tahun 2016. 
Putuhena, J.D. 2013. Model Dinamik Pengelolaan Daerah Aliran Sungai (Watershed) dalam Upaya Penyediaan Air yang Berkelanjutan di Semenanjung Leitimor Pulau Ambon. Disertasi. Institut Pertanian Bogor. Bogor.

Putuhena J. D., A. Sapei., M. T. Y. Purwanto., L. B. Prasetyo 2014. Sustainable Water Supply Model in Ambon Island. Journal of Environmental and Ecology. Vol 5 No. 2. Page 292-306. www.macrothink.org/jee.

Supriadi, D. 2017. Penetapan Kelas Kemampuan Lahan DAS Wae Batu Merah Kota Ambon Provinsi Maluku. Skripsi. Universitas Pattimura. Ambon.

Surat Keputusan Menteri Pertanian No. 837/Kpts/Um/11/1980 Tentang Kriteria dan Tata Cara Penetapan Hutan Lindung.

Widiatmaka, S.H. 2007. Evaluasi Kesesuaian Lahan \& Perencanaan Tataguna Lahan. Pertama, Gadjah Mada University Press. Yogyakarta. 370 hal. 